\title{
Predictive Optimal Matrix Converter Control for a Dynamic Voltage Restorer with Flywheel Energy Storage
}

\author{
Paulo Gambôa ${ }^{1,3,4}$, J. Fernando Silva2,3, \\ S. Ferreira Pinto 2,3 and Elmano Margato ${ }^{1,3,4}$ \\ ${ }^{1}$ Instituto Superior de Engenharia de Lisboa, DEEA, \\ ${ }^{2}$ DEEC, Instituto Superior Técnico, \\ ${ }^{3}$ Center for Innovation in Electrical and Energy Engineering, \\ ${ }^{4}$ Centro de Electrotecnia e Electrónica Industrial, \\ Portugal
}

\section{Introduction}

In recent years, Flywheel Energy Storage (FES) systems have been rediscovered by industry due to their advantages in comparison with other short term energy storage systems [1], [2], [3]. FES can be designed to protect critical loads against voltage sags, by using a Permanent Magnet Synchronous Motor (PMSM) and a matrix converter to control the power transfer process between the flywheel and the critical load. This arrangement eliminates the dc link capacitor needed in conventional back-to-back inverter rectifier systems.

The predictive discrete-time control of power converters has been outlined in [4], [5], [6], [7], and recently applied to matrix converters [8].

In this chapter, using FES and PMSM, a matrix converter based Dynamic Voltage Restorer (DVR) model is used to obtain the current references to control the matrix converter (section II). A detailed discrete-time dynamic model of the matrix converter is used to predict the expected values of the input and output currents for all the 27 possible output voltage vectors generated by the matrix converter (section III). A minimization procedure, based on a weighted cost functional, selects the optimal vector that minimizes both the output current errors and the input current errors.

The predictive optimal controllers here proposed can enhance the controllability of matrix converters by optimizing the vector choice to overcome the input-output coupling of matrix converters, due to their lack of enough stored energy.

A description and characterization of an experimental kinetic energy accumulator, based on FES is also presented (section IV). The matrix based DVR simulation results are shown in section V. Results show that FES with predictive optimal matrix converter control can be used as a DVR (Fig. 1) to excel in the mitigation of voltage sags and swells as well as voltage distortion at critical loads. 


\section{Dynamic voltage restorer}

\subsection{The concept of flywheel energy storage based DVRs}

Power quality problems like voltage sags, swells and harmonics are a major concern of the industrial and commercial electrical consumers due to enormous loss in terms of time and money [10]. This is due to the advent of a large number of sophisticated electrical and electronic equipments, such as computers, programmable logic controllers, variable speed drives, and other accurate control systems.

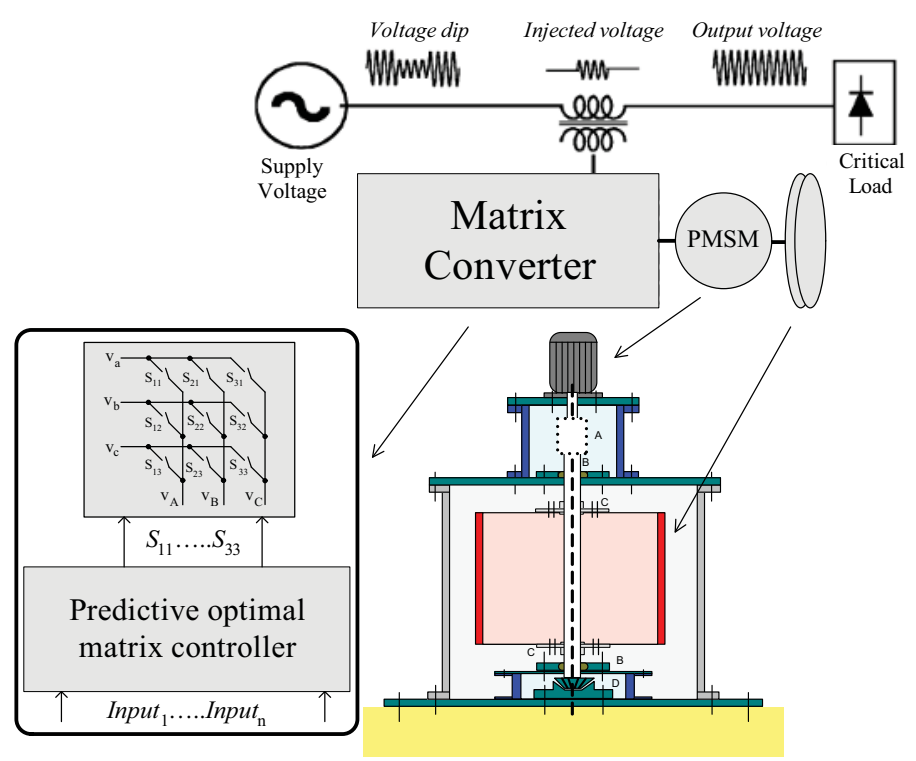

Fig. 1. Schematic diagram of a typical DVR.

The use of these equipments often requires very high quality power supplies. Some control equipments are highly sensitive to voltage disturbances, mainly voltage sags lasting several periods, which cause shut-downs and even failures. The adverse effects of voltage disturbances, such as sags and swells, dictated the need for effective mitigating devices. These devices include uninterruptible power supplies (UPS) and DVRs.

The DVR is one the most effective solutions for sags, since it only supplies the power difference between disturbed voltage and ideal voltages, not all the load power, as do UPSs. DVRs are series custom power devices, which should present excellent dynamic capabilities, to protect sensitive loads from voltage sags, swells and voltage harmonics, by inserting a compensating series voltage to restore the ideal network voltage waveform. Therefore, a DVR is basically a controlled voltage source installed in series between the supply and a sensitive load. It injects a voltage on the system in order to compensate any disturbance affecting the load voltage. Basic operating diagram of a DVR is as shown in Fig. 2, where the series voltage is inserted as the voltage on one winding of a transformer driven from the $R L$ output filter of the matrix converter. 


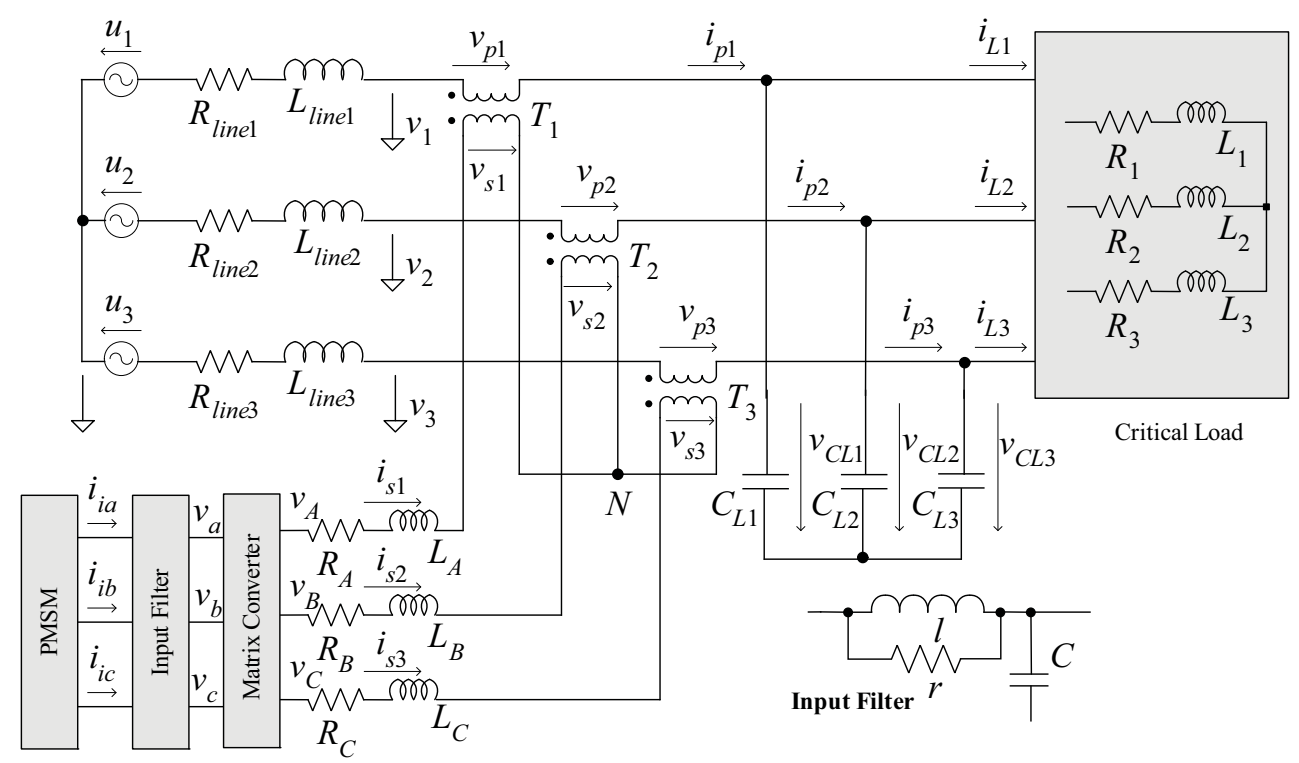

Fig. 2. Schematic diagram of a typical DVR.

\subsection{Critical load voltage control using DVRs}

To impose the compensating voltage, the needed critical load voltage components in the $d q$ frame $v_{C L d}, v_{C L q}$ must be controlled by acting on the matrix converter output current component references $i_{\text {sdref, }} i_{\text {sqref, }}$ using PI controllers [11], [12].

Gains $k_{p}$ and $k_{i}$ are respectively proportional and integral gains, which can be calculated optimizing the resulting closed loop $2^{\text {nd }}$ order system response. The reference values $i_{\text {sdref, }}$ $i_{\text {sqref }}$ will then be transformed into the $\alpha \beta$ frame to establish the references for a predictive current controller for the matrix converter.

Applying the Kirchhoff laws to the critical load (Fig.2) and doing some mathematical manipulations, the dynamic equations of the ac voltages $v_{C L 1}(t), v_{C L 2}(t)$ e $v_{C L 3}(t)$, are defined as functions of the circuit parameters and ac currents $i_{p 1}(t), i_{p 2}(t), i_{p 3}(t)$ and $i_{L 1}(t), i_{L 2}(t), i_{L 3}(t)$. The resultant state-space systems model is written in (1). The $i_{p 1}=N_{2} / N_{1} i_{s 1}, i_{p 2}=N_{2} / N_{1} i_{s 2}$ and $i_{p 3}=N_{2} / N_{1} i_{s 3}$ is the transformer turns ratio. In this model, the control variables are the output currents of the matrix converter, $i_{s 1}, i_{s 2}$ and $i_{s 3}$. The currents in the critical load, $i_{\mathrm{L} 1}, i_{\mathrm{L} 2}$ and $i_{\mathrm{L} 3}$ are disturbances for the design of controllers.

$$
\left[\begin{array}{l}
\frac{d v_{C L 1}}{d t} \\
\frac{d v_{C L 2}}{d t} \\
\frac{d v_{C L 3}}{d t}
\end{array}\right]=\left[\begin{array}{ccc}
\frac{1}{C_{L}} \frac{N_{2}}{N_{1}} & 0 & 0 \\
0 & \frac{1}{C_{L}} \frac{N_{2}}{N_{1}} & 0 \\
0 & 0 & \frac{1}{C_{L}} \frac{N_{2}}{N_{1}}
\end{array}\right]\left[\begin{array}{c}
i_{s 1} \\
i_{s 2} \\
i_{s 3}
\end{array}\right]-\left[\begin{array}{ccc}
\frac{1}{C_{L}} & 0 & 0 \\
0 & \frac{1}{C_{L}} & 0 \\
0 & 0 & \frac{1}{C_{L}}
\end{array}\right]\left[\begin{array}{l}
i_{L 1} \\
i_{L 2} \\
i_{L 3}
\end{array}\right]
$$


To design the critical load voltage, the system model (1) can advantageously be represented in $\alpha \beta$ coordinates. The relationship between the variables $X_{123}$ represented in system coordinates and in $\alpha \beta$ coordinates, $X_{\alpha \beta}$, is

$$
X_{123}=[C] X_{\alpha \beta}
$$

Where $C$ is the Concordia transformation (3).

$$
C=\sqrt{\frac{2}{3}}\left[\begin{array}{ccc}
1 & 0 & \frac{\sqrt{2}}{2} \\
-\frac{1}{2} & \frac{\sqrt{3}}{2} & \frac{\sqrt{2}}{2} \\
-\frac{1}{2} & -\frac{\sqrt{3}}{2} & \frac{\sqrt{2}}{2}
\end{array}\right]
$$

Applying (2) and (3) to the model (1), the critical load voltage model (4) in $\alpha \beta$ coordinates is obtained (without homopolar component).

$$
\left[\begin{array}{l}
\frac{d v_{C L \alpha}}{d t} \\
\frac{d v_{C L \beta}}{d t}
\end{array}\right]=\left[\begin{array}{cc}
\frac{1}{C_{L}} \frac{N_{2}}{N_{1}} & 0 \\
0 & \frac{1}{C_{L}} \frac{N_{2}}{N_{1}}
\end{array}\right]\left[\begin{array}{l}
i_{s \alpha} \\
i_{s \beta}
\end{array}\right]-\left[\begin{array}{cc}
\frac{1}{C_{L}} & 0 \\
0 & \frac{1}{C_{L}}
\end{array}\right]\left[\begin{array}{l}
i_{L \alpha} \\
i_{L \beta}
\end{array}\right]
$$

The relationship between the variables $X_{\alpha \beta}$ in represented in $\alpha \beta$ coordinates and in dq coordinates, $\mathrm{X}_{\mathrm{dq}}$, is given by the Park transformation:

$$
\begin{gathered}
X_{\alpha \beta}=D X_{d q} \\
D=\left[\begin{array}{cc}
\cos \theta & -\sin \theta \\
\sin \theta & \cos \theta
\end{array}\right]
\end{gathered}
$$

The argument $\theta=\omega t$ is the angular phase of the electrical network ac line voltage. Applying the Park transformation (5) to the critical load voltage model (4), in dq coordinates is obtained.

$$
\left[\begin{array}{l}
\frac{d v_{C L d}}{d t} \\
\frac{d v_{C L q}}{d t}
\end{array}\right]=\left[\begin{array}{cc}
0 & \omega \\
-\omega & 0
\end{array}\right]\left[\begin{array}{l}
v_{C L d} \\
v_{C L q}
\end{array}\right]+\left[\begin{array}{cc}
\frac{1}{C_{L}} \frac{N_{2}}{N_{1}} & 0 \\
0 & \frac{1}{C_{L}} \frac{N_{2}}{N_{1}}
\end{array}\right]\left[\begin{array}{l}
i_{s d} \\
i_{s q}
\end{array}\right]-\left[\begin{array}{cc}
\frac{1}{C_{L}} & 0 \\
0 & \frac{1}{C_{L}}
\end{array}\right]\left[\begin{array}{l}
i_{L d} \\
i_{L q}
\end{array}\right]
$$

The mathematical model needed to control the critical load voltage at the load shunt capacitors $C_{L 1}=C_{L 2}=C_{L 3}=C_{L}$ (Fig. 2), which serve as a load filter and power factor compensation, can be written in the dq frame as:

$$
\frac{d v_{C L d}}{d t}=\frac{1}{C_{L}}\left(C_{L} \omega v_{C L q}+\frac{N_{2}}{N_{1}} i_{s d}-i_{L d}\right)
$$




$$
\frac{d v_{c q}}{d t}=\frac{1}{C_{L}}\left(-C_{L} \omega v_{C L d}+\frac{N_{2}}{N_{1}} i_{s q}-i_{L q}\right)
$$

Where $N_{2} / N_{1}$ is the transformer turns ratio and $i_{s d}$ and $i_{s q}$ are direct and quadrature secondary current components in the transformer. This voltage dynamics is cross-coupled, but can be decoupled introducing auxiliary variables $h_{d}, h_{q}$ given by:

$$
\begin{gathered}
h_{d}=C_{L} \omega v_{C L q}+\frac{N_{2}}{N_{1}} i_{s d} \\
h_{q}=-C_{L} \omega v_{C L d}+\frac{N_{2}}{N_{1}} i_{s q}
\end{gathered}
$$

Substituting (10) and (11) in (8), (9), two isolated first order systems are obtained.

$$
\begin{aligned}
& \frac{d v_{C L d}}{d t}=\frac{1}{C_{L}}\left(h_{d}-i_{L d}\right) \\
& \frac{d v_{C L q}}{d t}=\frac{1}{C_{L}}\left(h_{q}-i_{L q}\right)
\end{aligned}
$$

Then, the needed critical load voltage components $v_{C L d}, v_{C L q}$ can be controlled by acting on the matrix converter output current component references $i_{\text {sdref, }} i_{\text {sqref, }}$, using PI controllers (Fig. 3).

$$
\begin{aligned}
& h_{\text {dref }}=\left(k_{p d}+\frac{k_{i d}}{s}\right) e_{v C L d} \Leftrightarrow h_{\text {dref }}=\left(k_{p d}+\frac{k_{i d}}{s}\right)\left(v_{C L d r e f}-v_{C L d}\right) \\
& h_{\text {qref }}=\left(k_{p q}+\frac{k_{i q}}{s}\right) e_{v C L q} \Leftrightarrow h_{\text {qref }}=\left(k_{p q}+\frac{k_{i q}}{s}\right)\left(v_{C L q r e f}-v_{C L q}\right)
\end{aligned}
$$

Substituting $i_{s d}=i_{\text {sdref }}$ and $h_{d}=h_{\text {dref }}$ in (10) and $i_{s q}=i_{\text {sqref }}$ and $h_{q}=h_{\text {qref }}$ in (11), the references $i_{s d r e f,}$ $i_{\text {sqref, }}$, are obtained.

$$
\begin{gathered}
h_{d}=C_{L} \omega v_{C L q}+\frac{N_{2}}{N_{1}} i_{s d} \Leftrightarrow i_{s d}=\frac{N_{1}}{N_{2}} h_{d}-C_{L} \frac{N_{1}}{N_{2}} \omega v_{C L q} \frac{N_{s d}=i_{\text {sdref }}}{h_{d}=h_{\text {dref }}} \rightarrow i_{\text {sdref }}=\frac{N_{1}}{N_{2}} h_{\text {dref }}-C_{L} \frac{N_{1}}{N_{2}} \omega v_{C L q} \\
h_{q}=-C_{L} \omega v_{C L d}+\frac{N_{2}}{N_{1}} i_{s q} \Leftrightarrow i_{s q}=\frac{N_{1}}{N_{2}} h_{q}+C_{L} \frac{N_{1}}{N_{2}} \omega v_{C L d} \frac{N_{i}}{\substack{i_{s q}=i_{\text {sqref }} \\
h_{q}=h_{q r e f}}} i_{\text {sqref }}=\frac{N_{1}}{N_{2}} h_{\text {qref }}+C_{L} \frac{N_{1}}{N_{2}} \omega v_{C L d}
\end{gathered}
$$

Substituting (14) in (16) and (15) in (17), the matrix converter output current component references $i_{\text {sdref, }} i_{\text {sqref, }}$ are given by (18) and (19).

$$
i_{\text {sdref }}=\frac{N_{1}}{N_{2}} k_{p}\left(v_{C L d r e f}-v_{C L d}\right)+\frac{N_{1}}{N_{2}} k_{i} \int\left(v_{C L d r e f}-v_{C L d}\right) d t-\frac{N_{1}}{N_{2}} C_{L} \omega v_{C L q}
$$




$$
i_{\text {sqref }}=\frac{N_{1}}{N_{2}} k_{p}\left(v_{C L q r e f}-v_{C L q}\right)+\frac{N_{1}}{N_{2}} k_{i} \int\left(v_{C L q r e f}-v_{C L q}\right) d t+\frac{N_{1}}{N_{2}} C_{L} \omega v_{C L d}
$$

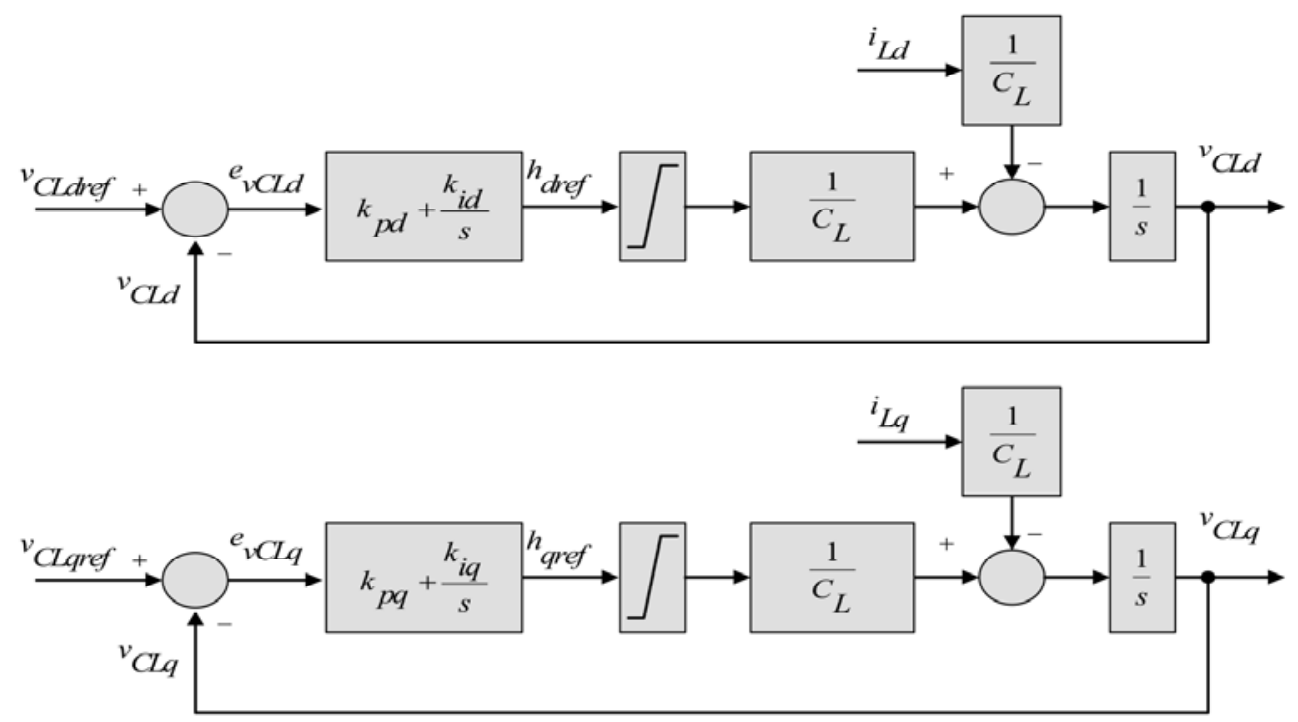

Fig. 3. Block diagram of the voltage components $v_{C L d}$ and $v_{C L q}$.

Gains $k_{p d q}(22)$ and $k_{i d q}(23)$ are respectively proportional and integral gains, which can be calculated minimizing the ITAE criterion in the resulting closed loop $2^{\text {nd }}$ order system $(20,21)$, provided the zeros $-k_{i d q} / k_{p d q}$ are far from the poles.

$$
\begin{gathered}
v_{C L d}=\frac{\frac{k_{p d}}{C_{L}} s+\frac{k_{i d}}{C_{L}}}{s^{2}+\frac{k_{p d}}{C_{L}} s+\frac{k_{i d}}{C_{L}}} v_{C L d r e f}-\frac{\frac{1}{C_{L}} s}{s^{2}+\frac{k_{p d}}{C_{L}} s+\frac{k_{i d}}{C_{L}}} i_{L d} \\
v_{C L q}=\frac{\frac{k_{p q}}{C_{L}} s+\frac{k_{i q}}{C_{L}}}{s^{2}+\frac{k_{p q}}{C_{L}} s+\frac{k_{i q}}{C_{L}}} v_{C L q r e f}-\frac{\frac{1}{C_{L}} s}{s^{2}+\frac{k_{p q}}{C_{L}} s+\frac{k_{i q}}{C_{L}}} i_{L q} \\
k_{p d}=k_{p q}=2 \xi \sqrt{C_{L} k_{i d q}} \\
k_{i d}=k_{i q}=C_{L} \omega_{n}^{2}
\end{gathered}
$$

The reference values $i_{\text {sdref, }} i_{\text {sqref }}$ will then be transformed into the $\alpha \beta$ frame to establish the references for a predictive current controller for the matrix converter. 


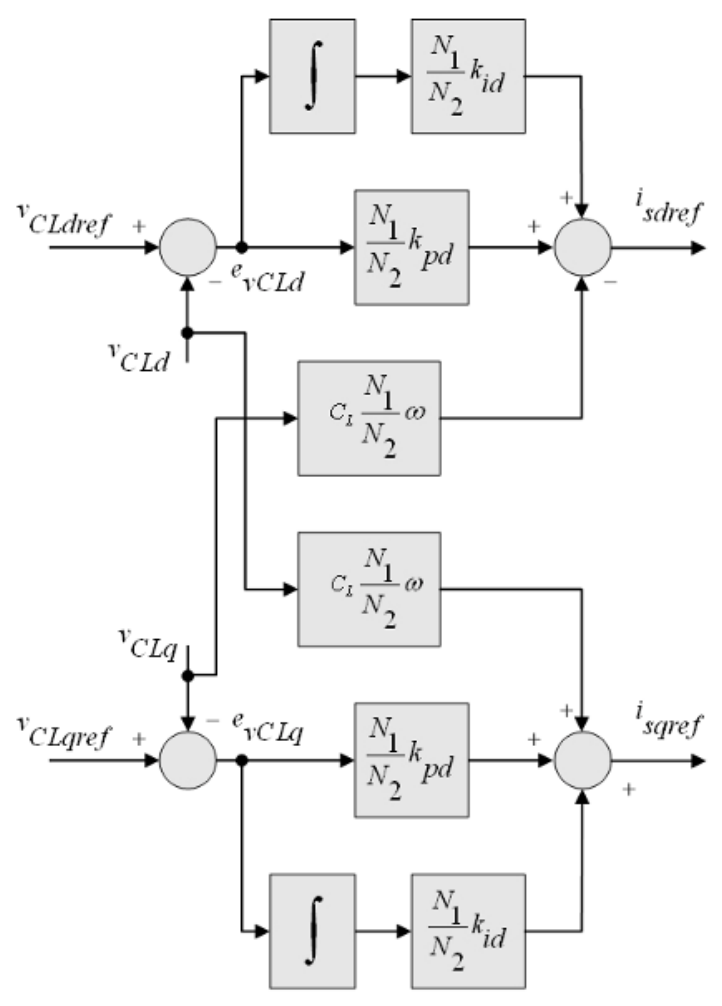

Fig. 4. Block diagram of the reference values components $i_{\text {sdref }}$ and $i_{\text {sqref. }}$.

\section{Predictive control of matrix converters for DVR operation}

\subsection{Matrix converter}

Matrix converters are based upon an association of nine bi-directional switches with turn-off capability, which allow the connection of each one of the three output phases to any one of the three input phases connected to a PMSM through a $r l C$ filter (Fig. 5).

A nine-element matrix, with elements $S_{i j}$ representing the state of each bi-directional switch, is used to represent the matrix output voltages $\left(v_{A}, v_{B}, v_{C}\right)$ as functions of the input voltages $\left(v_{a}, v_{b}, v_{c}\right)(24)$.

$$
\left[\begin{array}{l}
v_{A} \\
v_{B} \\
v_{C}
\end{array}\right]=\left[\begin{array}{lll}
S_{11} & S_{12} & S_{13} \\
S_{21} & S_{22} & S_{23} \\
S_{31} & S_{32} & S_{33}
\end{array}\right]\left[\begin{array}{l}
v_{a} \\
v_{b} \\
v_{c}
\end{array}\right]
$$

The line to line output voltages $\left(v_{A B}, v_{B C}, v_{C A}\right)$ are functions of the $S_{i j}$ and of the input line to line voltages $\left(v_{a b}, v_{b c}, v_{c a}\right)$ : 
$\left[\begin{array}{l}v_{A B} \\ v_{B C} \\ v_{C A}\end{array}\right]=\left[\begin{array}{lll}\frac{2}{3}\left(S_{11}-S_{21}\right)+\frac{1}{3}\left(S_{13}-S_{23}\right) & \frac{1}{3}\left(S_{11}-S_{21}\right)+\frac{2}{3}\left(S_{12}-S_{22}\right) & \frac{1}{3}\left(S_{12}-S_{22}\right)+\frac{2}{3}\left(S_{13}-S_{23}\right) \\ \frac{2}{3}\left(S_{21}-S_{31}\right)+\frac{1}{3}\left(S_{23}-S_{33}\right) & \frac{1}{3}\left(S_{21}-S_{31}\right)+\frac{2}{3}\left(S_{22}-S_{32}\right) & \frac{1}{3}\left(S_{22}-S_{32}\right)+\frac{2}{3}\left(S_{23}-S_{33}\right) \\ \frac{2}{3}\left(S_{31}-S_{11}\right)+\frac{1}{3}\left(S_{33}-S_{13}\right) & \frac{1}{3}\left(S_{31}-S_{11}\right)+\frac{2}{3}\left(S_{32}-S_{12}\right) & \frac{1}{3}\left(S_{32}-S_{12}\right)+\frac{2}{3}\left(S_{33}-S_{13}\right)\end{array}\right]\left[\begin{array}{l}v_{a b} \\ v_{b c} \\ v_{c a}\end{array}\right]$

Each $S_{i j}$ element of the $3 \times 3$ matrix represents the state of each bi-directional switch (if switch $S_{i j}$ is off then $S_{i j}=0$, else $\left.S_{i j}=1\right)$.

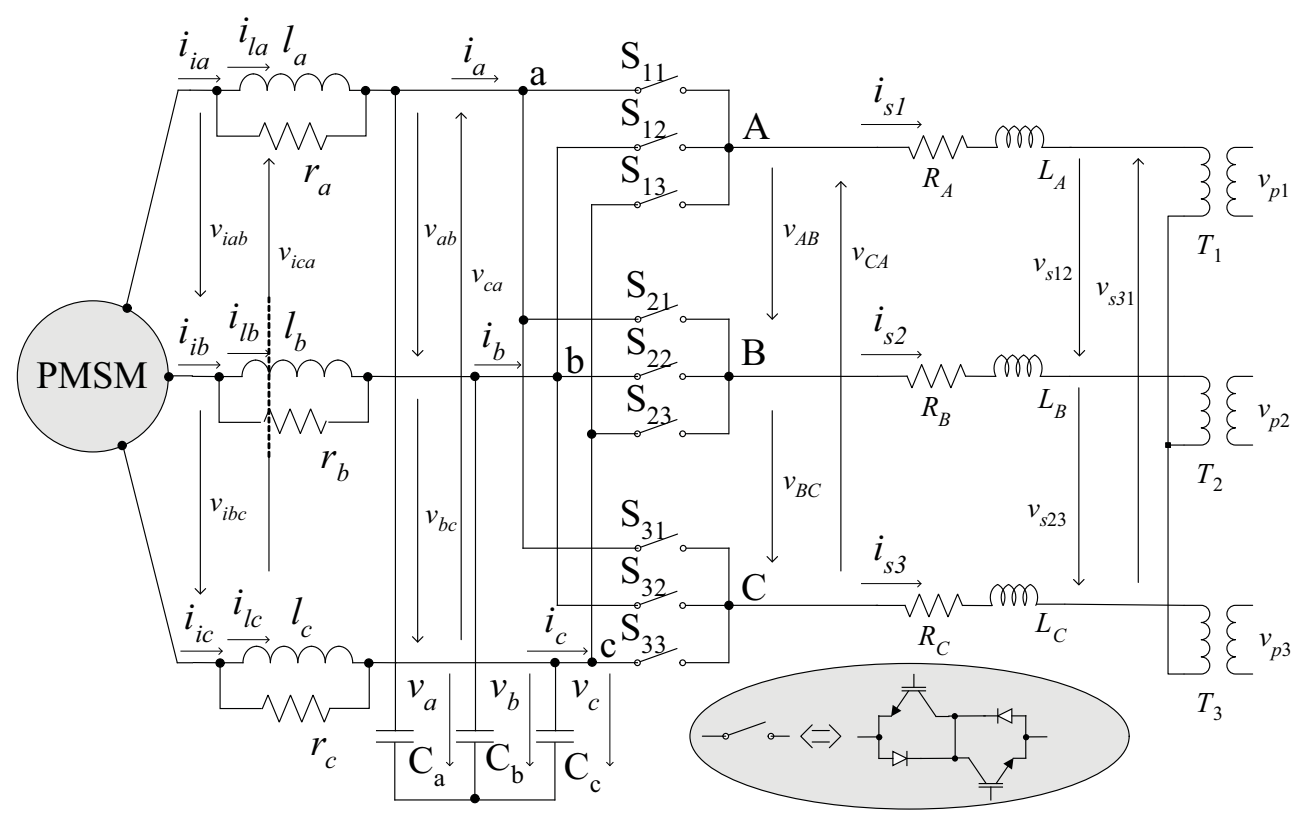

Fig. 5. Matrix converter topology.

The 3-phase matrix converter presents 27 switching combinations, or vectors [10], since for all $k \in\{1,2,3\} \sum_{j=1}^{3} S_{k j}=1$.

The input phase currents $\left(i_{a}, i_{b}, i_{c}\right)$ can be related to the output phase currents $\left(i_{s 1}, i_{s 2}, i_{s 3}\right)$ by:

$$
\left[\begin{array}{l}
i_{a} \\
i_{b} \\
i_{c}
\end{array}\right]=\left[\begin{array}{lll}
S_{11} & S_{21} & S_{31} \\
S_{12} & S_{22} & S_{32} \\
S_{13} & S_{23} & S_{33}
\end{array}\right]\left[\begin{array}{l}
i_{s 1} \\
i_{s 2} \\
i_{s 3}
\end{array}\right]
$$

The 27 switching combinations of the nine bi-directional switches $S_{i j}$ (Table 1), can be used as output voltage and/or input current vectors given as functions of each $S_{i j}$ state, meaning that the control of the matrix output voltages and matrix input $r l C$ filter currents (Fig. 5) is not independent. 


\begin{tabular}{|c|c|c|c|c|c|c|c|c|c|c|c|c|}
\hline $\mathrm{N}^{\circ}{ }^{\circ}$ & $S_{11}$ & $S_{12}$ & $S_{13}$ & $S_{21}$ & $S_{22}$ & $S_{23}$ & $S_{31}$ & $S_{32}$ & $S_{33}$ & $v_{A}(t)$ & $v_{B}(t)$ & $v_{C}(t)$ \\
\hline 1 & 1 & 0 & 0 & 0 & 1 & 0 & 0 & 0 & 1 & $v_{a}(t)$ & $v_{b}(t)$ & $v_{c}(t)$ \\
\hline 2 & 0 & 1 & 0 & 0 & 0 & 1 & 1 & 0 & 0 & $v_{b}(t)$ & $v_{c}(t)$ & $v_{a}(t)$ \\
\hline 3 & 0 & 0 & 1 & 1 & 0 & 0 & 0 & 1 & 0 & $v_{c}(t)$ & $v_{a}(t)$ & $v_{b}(t)$ \\
\hline 4 & 1 & 0 & 0 & 0 & 0 & 1 & 0 & 1 & 0 & $v_{a}(t)$ & $v_{c}(t)$ & $v_{b}(t)$ \\
\hline 5 & 0 & 1 & 0 & 1 & 0 & 0 & 0 & 0 & 1 & $v_{b}(t)$ & $v_{a}(t)$ & $v_{c}(t)$ \\
\hline 6 & 0 & 0 & 1 & 0 & 1 & 0 & 1 & 0 & 0 & $v_{c}(t)$ & $v_{b}(t)$ & $v_{a}(t)$ \\
\hline 7 & 1 & 0 & 0 & 0 & 1 & 0 & 0 & 1 & 0 & $v_{a}(t)$ & $v_{b}(t)$ & $v_{b}(t)$ \\
\hline 8 & 0 & 1 & 0 & 1 & 0 & 0 & 1 & 0 & 0 & $v_{b}(t)$ & $v_{a}(t)$ & $v_{a}(t)$ \\
\hline 9 & 0 & 1 & 0 & 0 & 0 & 1 & 0 & 0 & 1 & $v_{b}(t)$ & $v_{c}(t)$ & $v_{c}(t)$ \\
\hline 10 & 0 & 0 & 1 & 0 & 1 & 0 & 0 & 1 & 0 & $v_{c}(t)$ & $v_{b}(t)$ & $v_{b}(t)$ \\
\hline 11 & 0 & 0 & 1 & 1 & 0 & 0 & 1 & 0 & 0 & $v_{c}(t)$ & $v_{a}(t)$ & $v_{a}(t)$ \\
\hline 12 & 1 & 0 & 0 & 0 & 0 & 1 & 0 & 0 & 1 & $v_{a}(t)$ & $v_{c}(t)$ & $v_{c}(t)$ \\
\hline 13 & 0 & 1 & 0 & 1 & 0 & 0 & 0 & 1 & 0 & $v_{b}(t)$ & $v_{a}(t)$ & $v_{b}(t)$ \\
\hline 14 & 1 & 0 & 0 & 0 & 1 & 0 & 1 & 0 & 0 & $v_{a}(t)$ & $v_{b}(t)$ & $v_{a}(t)$ \\
\hline 15 & 0 & 0 & 1 & 0 & 1 & 0 & 0 & 0 & 1 & $v_{c}(t)$ & $v_{b}(t)$ & $v_{c}(t)$ \\
\hline 16 & 0 & 1 & 0 & 0 & 0 & 1 & 0 & 1 & 0 & $v_{b}(t)$ & $v_{c}(t)$ & $v_{b}(t)$ \\
\hline 17 & 1 & 0 & 0 & 0 & 0 & 1 & 1 & 0 & 0 & $v_{a}(t)$ & $v_{c}(t)$ & $v_{a}(t)$ \\
\hline 18 & 0 & 0 & 1 & 1 & 0 & 0 & 0 & 0 & 1 & $v_{c}(t)$ & $v_{a}(t)$ & $v_{c}(t)$ \\
\hline 19 & 0 & 1 & 0 & 0 & 1 & 0 & 1 & 0 & 0 & $v_{b}(t)$ & $v_{b}(t)$ & $v_{a}(t)$ \\
\hline 20 & 1 & 0 & 0 & 1 & 0 & 0 & 0 & 1 & 0 & $v_{a}(t)$ & $v_{a}(t)$ & $v_{b}(t)$ \\
\hline 21 & 0 & 0 & 1 & 0 & 0 & 1 & 0 & 1 & 0 & $v_{c}(t)$ & $v_{c}(t)$ & $v_{b}(t)$ \\
\hline 22 & 0 & 1 & 0 & 0 & 1 & 0 & 0 & 0 & 1 & $v_{b}(t)$ & $v_{b}(t)$ & $v_{c}(t)$ \\
\hline 23 & 1 & 0 & 0 & 1 & 0 & 0 & 0 & 0 & 1 & $v_{a}(t)$ & $v_{a}(t)$ & $v_{c}(t)$ \\
\hline 24 & 0 & 0 & 1 & 0 & 0 & 1 & 1 & 0 & 0 & $v_{c}(t)$ & $v_{c}(t)$ & $v_{a}(t)$ \\
\hline 25 & 1 & 0 & 0 & 1 & 0 & 0 & 1 & 0 & 0 & $v_{a}(t)$ & $v_{a}(t)$ & $v_{a}(t)$ \\
\hline 26 & 0 & 1 & 0 & 0 & 1 & 0 & 0 & 1 & 0 & $v_{b}(t)$ & $v_{b}(t)$ & $v_{b}(t)$ \\
\hline 27 & 0 & 0 & 1 & 0 & 0 & 1 & 0 & 0 & 1 & $v_{c}(t)$ & $v_{c}(t)$ & $v_{c}(t)$ \\
\hline
\end{tabular}

Table 1. Voltages vectors generated by the matrix converter

\subsection{Matrix converter input and output currents dynamic model}

Supposing a balanced three-phase inductive load, the first time derivative of the matrix converter output currents $\left(i_{s 1}, i_{s 2}, i_{s 3}\right)$ in the $\alpha \beta$ frame (Concordia transformation) can be defined by $(27,28)$, where $R_{A}=R_{B}=R_{C}=R$ are the parasitic resistances and $L_{A}=L_{B}=L_{C}=L$ are the output inductors of the matrix converter (Fig. 5), and $v_{o \alpha \beta}$ and $v_{s \alpha \beta}$ represent, respectively the line to line output voltage of the matrix converter and the $v_{p \alpha \beta}$ voltages reflected in the transformer secondary.

$$
\begin{aligned}
& \frac{d i_{s \alpha}}{d t}=-\frac{R}{L} i_{s \alpha}+\frac{1}{2 L} v_{o \alpha}+\frac{\sqrt{3}}{6 L} v_{o \beta}-\frac{1}{2 L} v_{s \alpha}-\frac{\sqrt{3}}{6 L} v_{s \beta} \\
& \frac{d i_{s \beta}}{d t}=-\frac{R}{L} i_{s \beta}-\frac{\sqrt{3}}{6 L} v_{o \alpha}+\frac{1}{2 L} v_{o \beta}+\frac{\sqrt{3}}{6 L} v_{s \alpha}-\frac{1}{2 L} v_{s \beta}
\end{aligned}
$$

This dynamic equation will be used to predict the matrix converter output currents. 
Assuming a $2^{\text {nd }}$ order matrix converter input filter (Fig. 5) with resistances $r_{a}=r_{b}=r_{c}=r$, indutances $l_{a}=l_{b}=l_{c}=l$ and capacitors $C_{a}=C_{b}=C_{c}=C_{\mathrm{Y}}$, the dynamics of each inductor current $\left(i_{l \alpha \beta}\right)$, the dynamics of the capacitor line to line voltages $\left(v_{c \alpha \beta}\right)$ and the input line to line filter voltage $\left(v_{i c \alpha \beta}\right)$, in the $\alpha \beta$ frame, is given by:

$$
\begin{gathered}
\frac{d i_{l \alpha}}{d t}=\frac{1}{l} v_{i c \alpha}-\frac{1}{2 l} v_{c \alpha}-\frac{\sqrt{3}}{6 l} v_{c \beta} \\
\frac{d i_{l \beta}}{d t}=\frac{1}{l} v_{i c \beta}+\frac{\sqrt{3}}{6 l} v_{c \alpha}-\frac{1}{2 l} v_{c \beta} \\
\frac{d v_{c \alpha}}{d t}=-\frac{3}{2 C_{\mathrm{Y}}} i_{\alpha}+\frac{\sqrt{3}}{2 C_{\mathrm{Y}}} i_{\beta}+\frac{3}{2 C_{\mathrm{Y}}} i_{l \alpha}-\frac{\sqrt{3}}{2 C_{\mathrm{Y}}} i_{l \beta}-\frac{1}{C_{\mathrm{Y}}} v_{c \alpha}+\frac{3}{2 C_{\mathrm{Y}}} v_{i c \alpha}-\frac{\sqrt{3}}{2 C_{\mathrm{Y}}} v_{i c \beta} \\
\frac{d v_{c \beta}}{d t}=-\frac{\sqrt{3}}{2 C_{\mathrm{Y}}} i_{\alpha}-\frac{3}{2 C_{\mathrm{Y}}} i_{\beta}+\frac{\sqrt{3}}{2 C_{\mathrm{Y}}} i_{l \alpha}+\frac{3}{2 C_{\mathrm{Y}}} i_{l \beta}-\frac{1}{C_{\mathrm{Y}}} v_{c \beta}+\frac{\sqrt{3}}{2 C_{\mathrm{Y}}} v_{i c \alpha}+\frac{3}{2 C_{\mathrm{Y}}} v_{i c \beta} \\
\frac{d i_{l \alpha}}{d t}=\frac{r}{l} i_{i \alpha}-\frac{r}{l} i_{l \alpha} \\
\frac{d i_{l \beta}}{d t}=\frac{r}{l} i_{i \beta}-\frac{r}{l} i_{l \beta}
\end{gathered}
$$

These dynamic equations will be used to predict the input filter currents $i_{i \alpha,} i_{i \beta}$.

\subsection{Discrete-time prediction of matrix input and output currents}

A first-order difference equation $(35,36)$, with a sampling time $T_{s}$, equivalent to the load current differential equation $(27,28)$, can be used to predict the expected values (EulerForward method) of $i_{s \sigma} i_{s \beta}$ at time instant $t_{s+1}$, given the values of $i_{s \sigma o} i_{s \beta}$ at the ts ${ }^{\text {th }}$ sampling instant.

$$
\begin{aligned}
& i_{s \alpha}\left(t_{s+1}\right)=\left(1-\frac{R T_{s}}{L}\right) i_{s \alpha}\left(t_{s}\right)+\frac{T_{s}}{2 L} v_{o \alpha}\left(t_{s}\right)+\frac{\sqrt{3} T_{s}}{6 L} v_{o \beta}\left(t_{s}\right)-\frac{T_{s}}{2 L} v_{s \alpha}\left(t_{s}\right)-\frac{\sqrt{3} T_{s}}{6 L} v_{s \beta}\left(t_{s}\right) \\
& i_{s \beta}\left(t_{s+1}\right)=\left(1-\frac{R T_{s}}{L}\right) i_{s \beta}\left(t_{s}\right)-\frac{\sqrt{3} T_{s}}{6 L} v_{o \alpha}\left(t_{s}\right)+\frac{T_{s}}{2 L} v_{o \beta}\left(t_{s}\right)+\frac{\sqrt{3} T_{s}}{6 L} v_{s \alpha}\left(t_{s}\right)-\frac{T_{s}}{2 L} v_{s \beta}\left(t_{s}\right)
\end{aligned}
$$

The voltages vectors $v_{o \alpha \beta}(37,38)$ can be generated by the matrix converter, and $v_{c \alpha \beta}$ represent the line to line input voltage in the $\alpha \beta$ frame (Concordia transformation).

$$
\begin{aligned}
& v_{o \alpha}\left(t_{s+1}\right)=H_{v \alpha \alpha}\left(t_{s+1}\right) v_{c \alpha}\left(t_{s}\right)+H_{v \alpha \beta}\left(t_{s+1}\right) v_{c \beta}\left(t_{s}\right) \\
& v_{o \beta}\left(t_{s+1}\right)=H_{v \beta \alpha}\left(t_{s+1}\right) v_{c \alpha}\left(t_{s}\right)+H_{v \beta \beta}\left(t_{s+1}\right) v_{c \beta}\left(t_{s}\right)
\end{aligned}
$$

Where $H_{v \alpha o} H_{v \alpha \beta}, H_{v \beta \alpha}$ and $H_{v \beta \beta}$ is given by (39). 


$$
\left\{\begin{array}{l}
H_{v \alpha \alpha}=\frac{1}{2}\left(S_{11}-S_{12}-S_{21}+S_{22}\right) \\
H_{v \alpha \beta}=\frac{\sqrt{3}}{6}\left(S_{11}+S_{12}-2 S_{13}-S_{21}-S_{22}+2 S_{23}\right) \\
H_{v \beta \alpha}=\frac{\sqrt{3}}{6}\left(S_{11}-S_{12}+S_{21}-S_{22}-2 S_{31}+2 S_{32}\right) \\
H_{v \beta \beta}=\frac{1}{6}\left(S_{11}+S_{12}-2 S_{13}+S_{21}+S_{22}-2 S_{23}-2 S_{31}-2 S_{32}+4 S_{33}\right)
\end{array}\right.
$$

Applying Euler-Backward method to the model $(29,30)$ and $(31,32)$, the expected values of the $i l_{\alpha \beta}\left(t_{s+1}\right)$ are obtained. Applying Euler-Backward method to the model $(33,34)$ and replacing $i l_{\alpha \beta}\left(t_{s+1}\right)$, the expected values of the $i_{i \alpha \beta}\left(t_{s+1}\right)$ are obtained. The discrete-time difference equations $(40,41)$ (sampling time $T_{s}$ ) of the matrix input filter current dynamic equations, can be used to predict the expected values of the input filter currents at the $t_{s+1}$ sampling instant.

$$
\begin{aligned}
i_{i \alpha}\left(t_{s+1}\right)= & \frac{C_{\mathrm{Y}} l r}{r T_{s}^{2}+l T_{s} r+C_{\mathrm{Y}} l r} i_{l \alpha}\left(t_{s}\right)+\frac{T_{s}\left(l+T_{s} r\right)}{r T_{s}^{2}+l T_{s} r+C_{\mathrm{Y}} l r} i_{\alpha}\left(t_{s+1}\right)+\frac{C_{\mathrm{Y}}\left(l+T_{s} r\right)}{2 r T_{s}^{2}+2 l T_{s} r+2 C_{\mathrm{Y}} l r} v_{i c \alpha}\left(t_{s+1}\right)+ \\
& +\frac{\sqrt{3} C_{\mathrm{Y}}\left(l+T_{s} r\right)}{6 r T_{s}^{2}+6 l T_{s} r+6 C_{\mathrm{Y}} l r} v_{i c \beta}\left(t_{s+1}\right)-\frac{C_{\mathrm{Y}}\left(l+T_{s} r\right)}{2 r T_{s}^{2}+2 l T_{s} r+2 C_{\mathrm{Y}} l r} v_{c \alpha}\left(t_{s}\right)-\frac{\sqrt{3} C_{\mathrm{Y}}\left(l+T_{s} r\right)}{6 r T_{s}^{2}+6 l T_{s} r+6 C_{\mathrm{Y}} l r} v_{c \beta}\left(t_{s}\right) \\
i_{i \beta}\left(t_{s+1}\right)= & \frac{C_{\mathrm{Y}} l r}{r T_{s}^{2}+l T_{s} r+C_{\mathrm{Y}} l r} i_{l \beta}\left(t_{s}\right)+\frac{T_{s}\left(l+T_{s} r\right)}{r T_{s}^{2}+l T_{s} r+C_{\mathrm{Y}} l r} i_{\beta}\left(t_{s+1}\right)-\frac{\sqrt{3} C_{\mathrm{Y}}\left(l+T_{s} r\right)}{6 r T_{s}^{2}+6 l T_{s} r+6 C_{\mathrm{Y}} l r} v_{i c \alpha}\left(t_{s+1}\right)+ \\
& +\frac{C_{\mathrm{Y}}\left(l+T_{s} r\right)}{2 r T_{s}^{2}+2 l T_{s} r+2 C_{\mathrm{Y}} l r} v_{i c \beta}\left(t_{s+1}\right)+\frac{\sqrt{3} C_{\mathrm{Y}}\left(l+T_{s} r\right)}{6 r T_{s}^{2}+6 l T_{s} r+6 C_{\mathrm{Y}} l r} v_{c \alpha}\left(t_{s}\right)-\frac{C_{\mathrm{Y}}\left(l+T_{s} r\right)}{2 r T_{s}^{2}+2 l T_{s} r+2 C_{\mathrm{Y}} l r} v_{c \beta}\left(t_{s}\right)
\end{aligned}
$$

Where, considering $(40,41)$, the matrix input currents $i_{a}\left(t_{s+1}\right), i_{b}\left(t_{s+1}\right)$ and $i_{c}\left(t_{s+1}\right)$, at the $t_{s+1}$ sampling instant are established by equations (42), (43) and (44).

$$
\begin{aligned}
& i_{a}\left(t_{s+1}\right)=S_{11}\left(t_{s+1}\right) i_{s 1}\left(t_{s}\right)+S_{21}\left(t_{s+1}\right) i_{s 2}\left(t_{s}\right)+S_{31}\left(t_{s+1}\right) i_{s 3}\left(t_{s}\right) \\
& i_{b}\left(t_{s+1}\right)=S_{12}\left(t_{s+1}\right) i_{s 1}\left(t_{s}\right)+S_{22}\left(t_{s+1}\right) i_{s 2}\left(t_{s}\right)+S_{32}\left(t_{s+1}\right) i_{s 3}\left(t_{s}\right) \\
& i_{c}\left(t_{s+1}\right)=S_{13}\left(t_{s+1}\right) i_{s 1}\left(t_{s}\right)+S_{23}\left(t_{s+1}\right) i_{s 2}\left(t_{s}\right)+S_{33}\left(t_{s+1}\right) i_{s 3}\left(t_{s}\right)
\end{aligned}
$$

Applying (2) and (3) to equations (42), (43) and (44), the input currents at the $t_{s+1}$ sampling instant, in $\alpha \beta$ coordinates is obtained $(45,46)$.

$$
\begin{aligned}
& i_{\alpha}\left(t_{s+1}\right)=H_{i \alpha \alpha}\left(t_{s+1}\right) i_{s \alpha}\left(t_{s}\right)+H_{i \alpha \beta}\left(t_{s+1}\right) i_{s \beta}\left(t_{s}\right) \\
& i_{\beta}\left(t_{s+1}\right)=H_{i \beta \alpha}\left(t_{s+1}\right) i_{s \alpha}\left(t_{s}\right)+H_{i \beta \beta}\left(t_{s+1}\right) i_{s \beta}\left(t_{s}\right)
\end{aligned}
$$

Where $H_{i \alpha \alpha} H_{i \alpha \beta \prime} H_{i \beta \alpha}$ and $H_{i \beta \beta}$ is given by (47). 


$$
\begin{aligned}
& H_{i \alpha \alpha}=\frac{2}{3} S_{11}-\frac{1}{3} S_{12}-\frac{1}{3} S_{13}-\frac{1}{3} S_{21}+\frac{1}{6} S_{22}+\frac{1}{6} S_{23}-\frac{1}{3} S_{31}+\frac{1}{6} S_{32}+\frac{1}{6} S_{33} \\
& H_{i \alpha \beta}=\frac{2 \sqrt{3}}{6} S_{21}-\frac{\sqrt{3}}{6} S_{22}-\frac{\sqrt{3}}{6} S_{23}-\frac{2 \sqrt{3}}{6} S_{31}+\frac{\sqrt{3}}{6} S_{32}+\frac{\sqrt{3}}{6} S_{33} \\
& H_{i \beta \alpha}=\frac{2 \sqrt{3}}{3} S_{12}-\frac{2 \sqrt{3}}{6} S_{13}-\frac{\sqrt{3}}{6} S_{22}+\frac{\sqrt{3}}{6} S_{23}-\frac{\sqrt{3}}{6} S_{32}+\frac{\sqrt{3}}{6} S_{33} \\
& H_{i \beta \beta}=\frac{1}{2} S_{22}-\frac{1}{2} S_{23}-\frac{1}{2} S_{32}+\frac{1}{2} S_{33}
\end{aligned}
$$

\subsection{Quadratic cost functional for the matrix output current errors and matrix input power factor error}

The $\alpha \beta$ errors $e_{s \alpha}$ (48) and $e_{s \beta}$ (49) of the matrix output currents $i_{s \alpha}$ and $i_{s \beta}$ are defined as differences between the current references $i_{s o r e f}$ and $i_{s \beta r e f}$ and the actual output currents $i_{s \alpha}$ and $i_{s \beta}$.

$$
\begin{aligned}
& e_{s \alpha}\left(t_{s+1}\right)=i_{\text {saref }}\left(t_{s}\right)-i_{s \alpha}\left(t_{s+1}\right) \\
& e_{s \beta}\left(t_{s+1}\right)=i_{s \beta r e f}\left(t_{s}\right)-i_{s \beta}\left(t_{s+1}\right)
\end{aligned}
$$

For the matrix input filter current errors, a near unity input power factor for the matrix converter is assumed. Then, the reactive power reference $Q_{\text {ref }}$ should be zero. Therefore, the reactive power error $e_{Q}$ is (50).

$$
e_{Q}\left(t_{s+1}\right)=Q_{r e f}-\left[-\frac{1}{2} v_{i c \alpha}\left(t_{s+1}\right) i_{i \beta}\left(t_{s+1}\right)-\frac{\sqrt{3}}{6} v_{i c \beta}\left(t_{s+1}\right) i_{i \beta}\left(t_{s+1}\right)-\frac{\sqrt{3}}{6} v_{i c \alpha}\left(t_{s+1}\right) i_{i \alpha}\left(t_{s+1}\right)+\frac{1}{2} v_{i c \beta}\left(t_{s+1}\right) i_{i \alpha}\left(t_{s+1}\right)\right]
$$

The input filter voltages $v_{i a b}, v_{i b c}$ and $v_{i c a}$ at the $\mathrm{t}_{\mathrm{s}+1}$ sampling instant, in $\alpha \beta$ coordinates is obtained $(51,52)$.

$$
\begin{aligned}
& v_{i c \alpha}\left(t_{s+1}\right)=v_{i c \alpha}\left(t_{s}\right) \cos \left(2 \pi f T_{s}\right)-v_{i c \beta}\left(t_{s}\right) \sin \left(2 \pi f T_{s}\right) \\
& v_{i c \beta}\left(t_{s+1}\right)=v_{i c \beta}\left(t_{s}\right) \cos \left(2 \pi f T_{s}\right)+v_{i c \alpha}\left(t_{s}\right) \sin \left(2 \pi f T_{s}\right)
\end{aligned}
$$

The cost functional to be chosen must penalize larger errors, while forgiving very small errors. Thus, the most suitable cost evaluator is a quadratic cost functional $F$ (53), which computes the norm of the weighted matrix output current errors and input power factor error.

$$
F=\sqrt{e_{s \alpha}^{2}\left(t_{s+1}\right) k_{\alpha}+e_{s \beta}^{2}\left(t_{s+1}\right) k_{\beta}+e_{Q}^{2}\left(t_{s+1}\right) k_{Q}}
$$

In the cost functional (53), $k_{\alpha}, k_{\beta}, k_{Q}$ are weighting constants, degrees of freedom of the predictive optimal controller. In Fig. 6 it is shown the predictive optimal matrix converter control algorithm. 


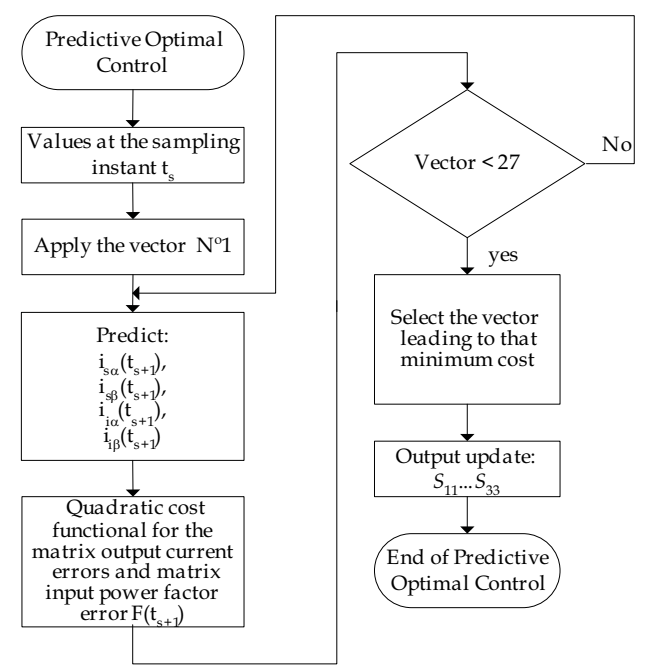

Fig. 6. Predictive Optimal Matrix Converter Control Algorithm.

\subsection{Predictive optimal matrix converter control}

The predictive optimal matrix controller uses the discrete-time model $(35,36,40,41)$ to predict, for the next sampling instant, the values of the input and output currents and the errors for all the 27 possible vectors of the matrix converter. An optimal algorithm (Fig. 7) minimizes input and output current errors using the minimum value of the weighted cost functional (53) evaluated for all 27 vectors, to select the vector leading to that minimum cost.

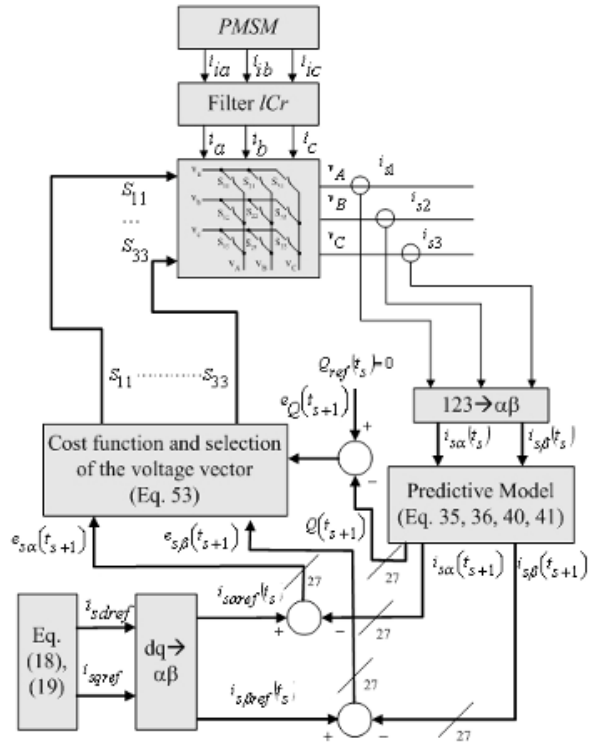

Fig. 7. Block diagram of the predictive optimal matrix converter control. 


\section{The experimental kinetic energy storage system}

\subsection{The concept of flywheel}

An experimental kinetic energy storage (Fig. 8, 9) was designed and built to have a moment of inertia of $4.2 \mathrm{kgm}^{2}$ and a maximum rotating speed of $2500 \mathrm{rpm}$.

A PMSM (2.9kW, 3000rpm) was selected as the electromechanical energy transfer device. A steel seamless tube (fig. 8) was selected as a rotating mass, given its availability and ease of assembly. This part of the device is characterized by parameters which depend on material (in this case steel), and parameters and dimensions of the barrel (Fig. 8).

The volume of the steel barrel is:

$$
V=2 \pi\left(r_{2}^{2}-r_{1}^{2}\right) h=0.0062 m^{3}
$$

Where $r_{1}, r_{2}$ are respectively the internal and external radius of the barrel. Its mass is:

$$
m=\rho V=70.0 \mathrm{~kg}
$$

Where $\rho=7.8 \times 10^{3}\left[\mathrm{~kg} / \mathrm{m}^{3}\right]$ is the steel density.

The moment of inertia is given as:

$$
J=\frac{1}{2} m\left(r_{2}^{2}+r_{1}^{2}\right)=4.2 \mathrm{kgm}^{2}
$$
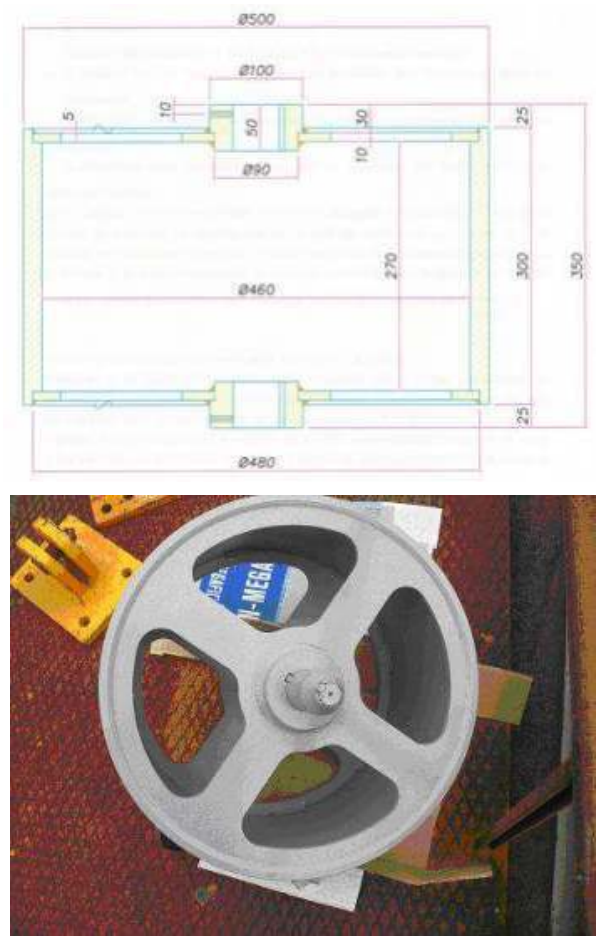

Fig. 8. Dimension and view of the steel barrel. 
Predictive Optimal Matrix Converter Control for a
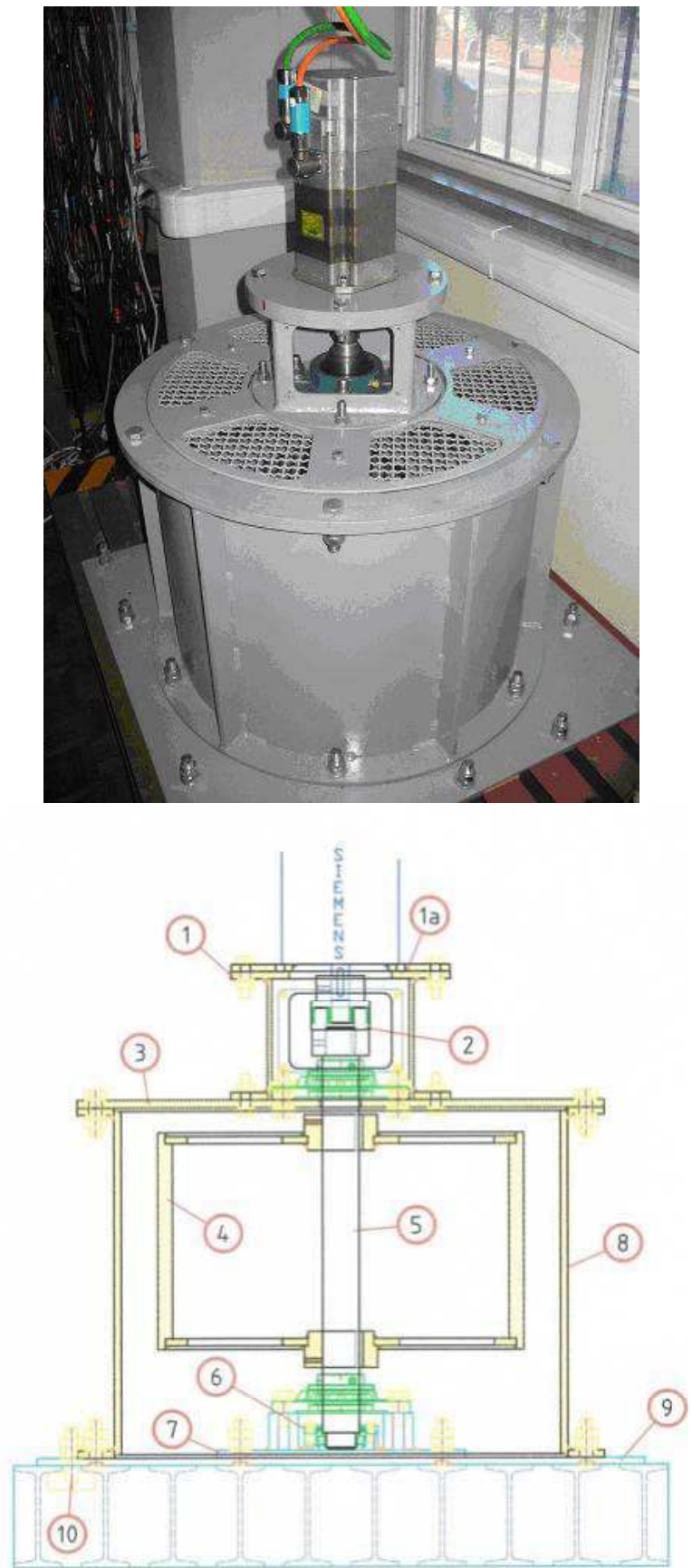

Fig. 9. Flywheel energy storage prototype. 
Using $r_{1}=250 \mathrm{~mm}, r_{2}=240 \mathrm{~mm}, m=70 \mathrm{~kg}$, and $\omega_{\max }=2500 \times 2 \pi / 60[\mathrm{rad} / \mathrm{s}]$ as the maximum angular speed of the barrel, the maximum energy stored in the FES is:

$$
E_{k \max }=\frac{1}{2} J \omega_{\max }^{2}=144 k J
$$

This energy cannot be completely extracted from the FES, as the energy conversion becomes inefficient when the angular speed drops below a certain value (roughly $50 \%$ of the rated speed) [11]. Supposing this limit equals $50 \%$ of the maximum speed, the amount of useful energy is $75 \%$ of the total energy and, in this case, $0.75 \times 144[\mathrm{~kJ}]=108[\mathrm{~kJ}]$. Given this energy, Fig. 10 relates the maximum power available from the flywheel for a given time. For example, if it is necessary to have power available during $0.5 \mathrm{~s}$, then nearly $200 \mathrm{~kW}$ can be supplied.

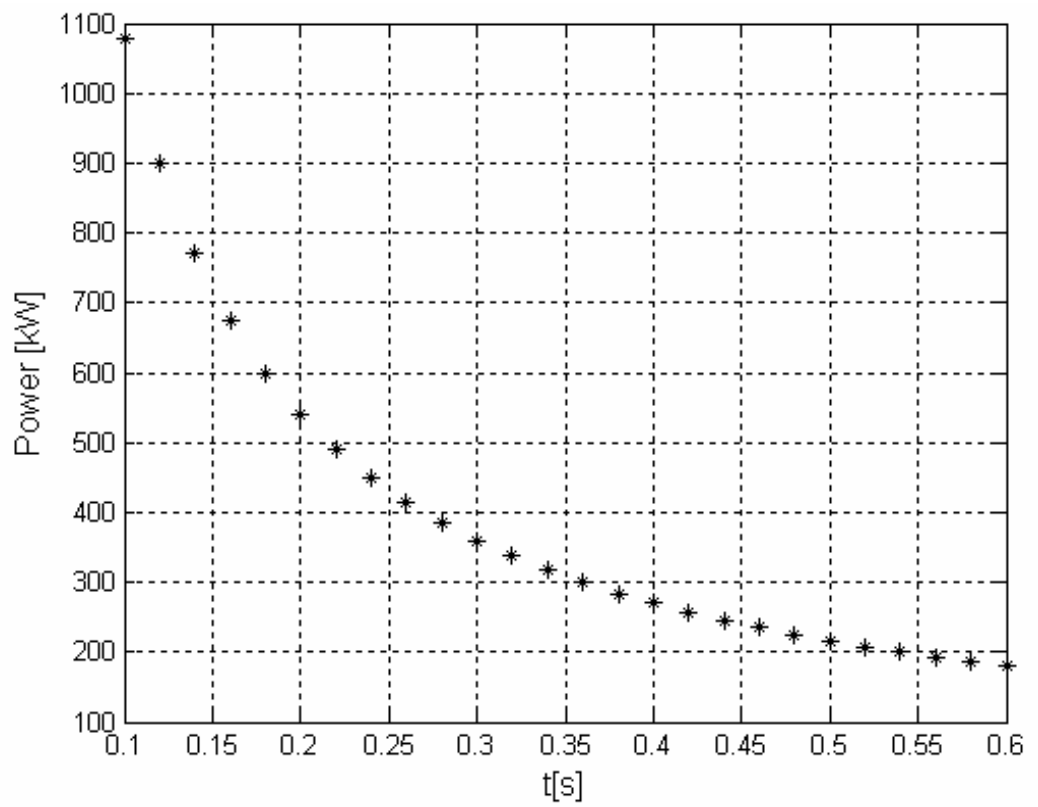

Fig. 10. Output power of the flywheel energy storage.

\subsection{Flywheel dynamics}

The Flywheel dynamics can be given as:

$$
T=J \frac{d \omega}{d t}+K_{D} \omega+K_{C}
$$

Where $J$ is the combined inertia of rotor PMSM and Flywheel, $K_{D}$ is the friction coefficient, $K_{C}$ is the Coulomb friction and $T$ is the resultant torque. To obtain parameters $K_{D}$ and $K_{C}$ an experimental deceleration (from 1500rpm to 0rpm) test was made (Fig. 11).

From Fig. 11, the flywheel parameters $K_{D}=0.01 \mathrm{Nms}$ and $K_{C}=1.04 \mathrm{Nms}$ can be obtained. 


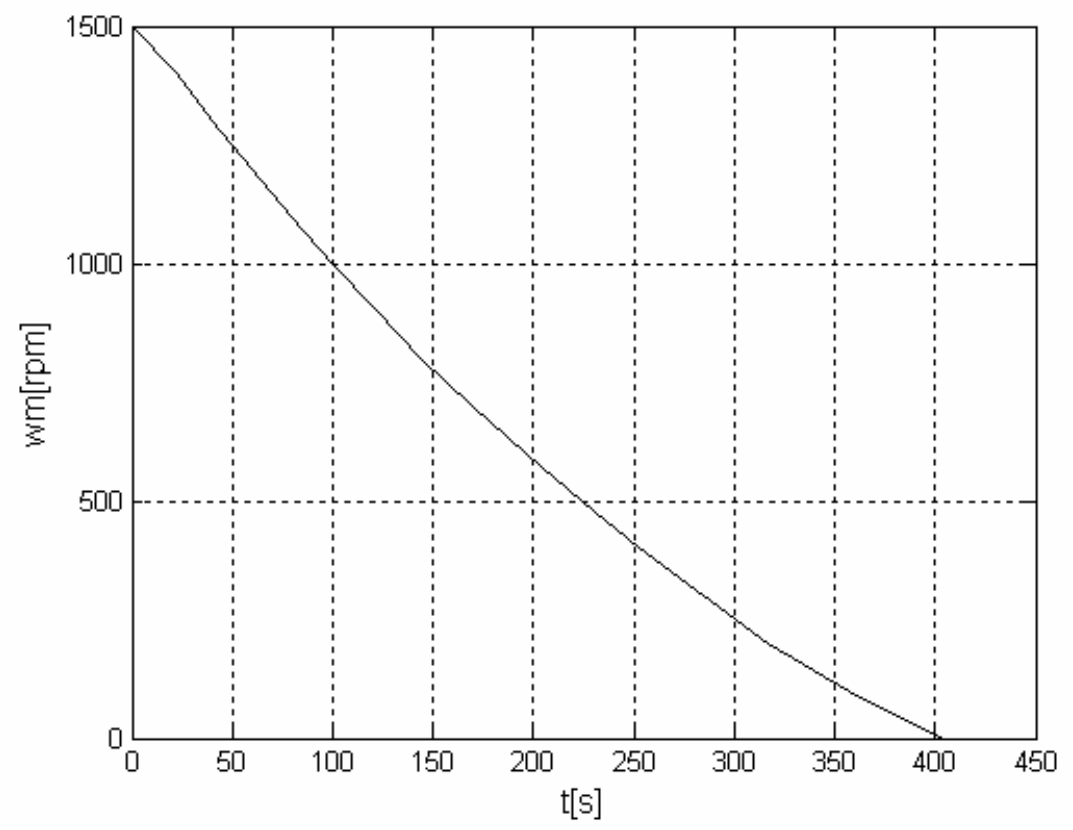

Fig. 11. Experimental results of flywheel deceleration.

In the project, design, construction and assembly in the laboratory were considered the following factors:

- $\quad$ Equilibrium of the moving parts for maximum angular speed of 2500rpm;

- Possibility of connecting several types of electric machines (Fig. 12);

- $\quad$ The vertical assembly was selected (Fig. 9);

- $\quad$ For security reasons, the flywheel is enclosed in another steel tube (Fig. 9);

- The wheel has a modular structure allowing easy assembly, disassembly and transportation;

- The flywheel total weight is about $350 \mathrm{~kg}$.

\subsection{Electric drive}

The Permanent Magnet Synchronous Motor (PMSM), manufacturer Siemens, model 1FK6063

- 6AF71 - 1AA0 (Fig. 12), has the following parameters:

- $\quad$ Rated speed: 3000rpm;

- Machine pole-pair number: 3

- $\quad$ Rated torque: $6 \mathrm{Nm}$;

- Rated current: 4.7A

- Inertia of rotor: $16.1 \times 10^{-4} \mathrm{kgm}^{2}$

- Torque constant: $1.39 \mathrm{Nm} / \mathrm{A}$

- $\quad$ Stator resistance: $0.83 \Omega$

- Rotating field inductance: $6.5 \mathrm{mH}$

- Incremental encoder with 2048ppr 


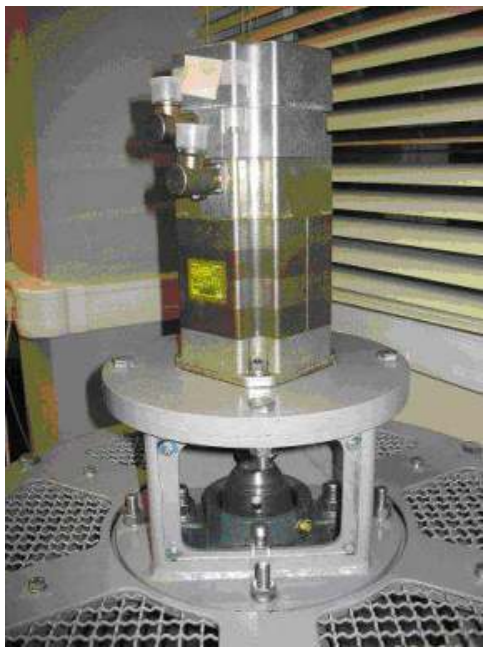

Fig. 12. View of the PMSM machine.

\subsection{Matrix converter}

The AC-AC Matrix Converter, supplying the machine, was built using the Eupec ECONOMAC matrix module (Fig. 13.a). As an example, Fig. 13.b shows one of the IGBT's drivers. The matrix converter input filter (Fig. 5) has the following parameters: $r_{a}=r_{b}=r_{c}=25 \Omega$; $l_{a}=l_{b}=l_{c}=6.5 \mathrm{mH}$ and $C_{a}=C_{b}=C_{c}=3 \times 6.8 \mu \mathrm{F}$. The matrix output inductor (Fig. 2) has the following parameters: $R_{A}=R_{B}=R_{C}=0.1 \Omega$ and $L_{A}=L_{B}=L_{C}=10 \mathrm{mH}$ [13].

The critical load and filter (Fig. 2) has parameters are: $R_{1}=R_{2}=R_{3}=100 \Omega, L_{1}=L_{2}=L_{3}=10 \mathrm{mH}$ and $C_{L 1}=C_{L 2}=C_{L 3}=5 \mu \mathrm{F}$.

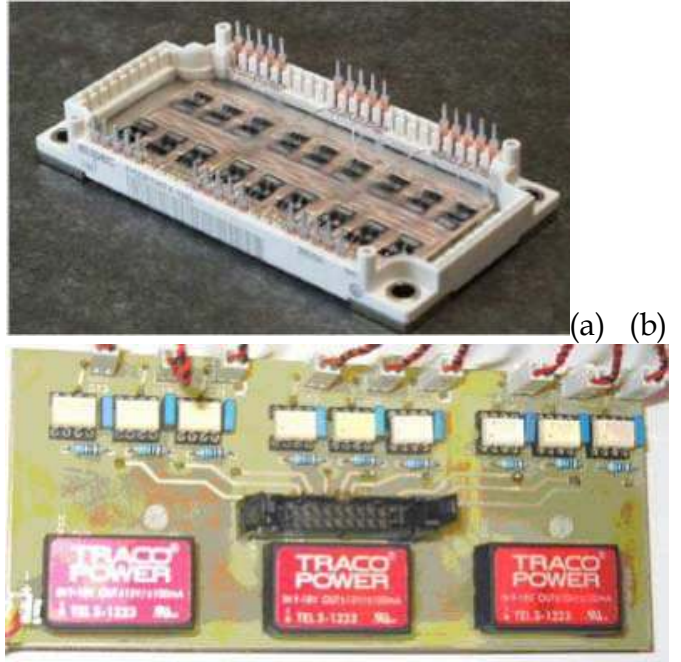

Fig. 13. a) The Eupec ECONOMAC matrix module; b) View of the gate driver printed circuit board. 


\section{DVR simulations results}

The matrix converter with input filter, PMSM, voltage source, series transformers, critical load and the real-time predictive optimal controller were simulated in the Matlab/Simulink environment to evaluate the performance of the proposed predictive optimal matrix converter based DVR.

The DVR with the matrix predictive controller is applied to compensate critical load voltage sags and swells. Two different tests were considered. In test 1 , mitigation of balanced and unbalanced voltage sags is evaluated. In test 2 the performance of the matrix DVR is demonstrated for balanced and unbalanced voltage swells. The total harmonic distortion (THD) of the critical load voltage is also evaluated.

\subsection{DVR response to voltage sags}

In the first test for balanced sags, it is assumed that there is a $40 \%$ three-phase voltage sag in the supply voltage, initiated at $0.6 \mathrm{~s}$ and lasting $0.08 \mathrm{~s}$. For unbalanced sags, $20 \%$ (phase 1 ) and $40 \%$ (phase 2 ) voltage dip is considered.

Fig. 14 (balanced sag $v_{s 123}$ ) and Fig. 15 (unbalanced sag $v_{s 123}$ ) show the result of the voltage sag compensation using the predictive optimal matrix converter control. The serial injected voltage components $\left(v_{p 123}\right)$ compensate the critical load voltage $\left(v_{C L 123}\right)$ without showing delays, voltage undershoots or overshoots. This illustrates the fast response of the predictive optimal controllers and the enhanced controllability of the matrix converter since their input-output interdependency does not disturb the critical load voltages, which are maintained balanced and at their nominal value $(400 \mathrm{~V})$.
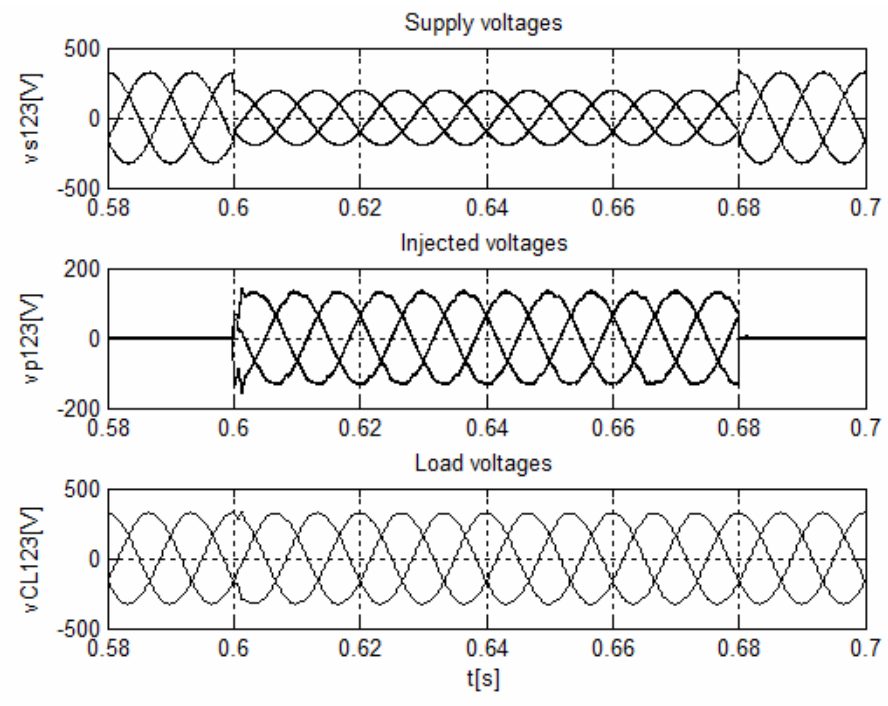

Fig. 14. Simulation result of DVR response to balanced voltage sag: Supply voltages $\left(v_{1}, v_{2}, v_{3}\right)$, Injected voltage $\left(v_{p 1}, v_{p 2}, v_{p 3}\right)$ and Load voltage $\left(v_{C L 1}, v_{C L 2}, v_{C L 3}\right)$. 

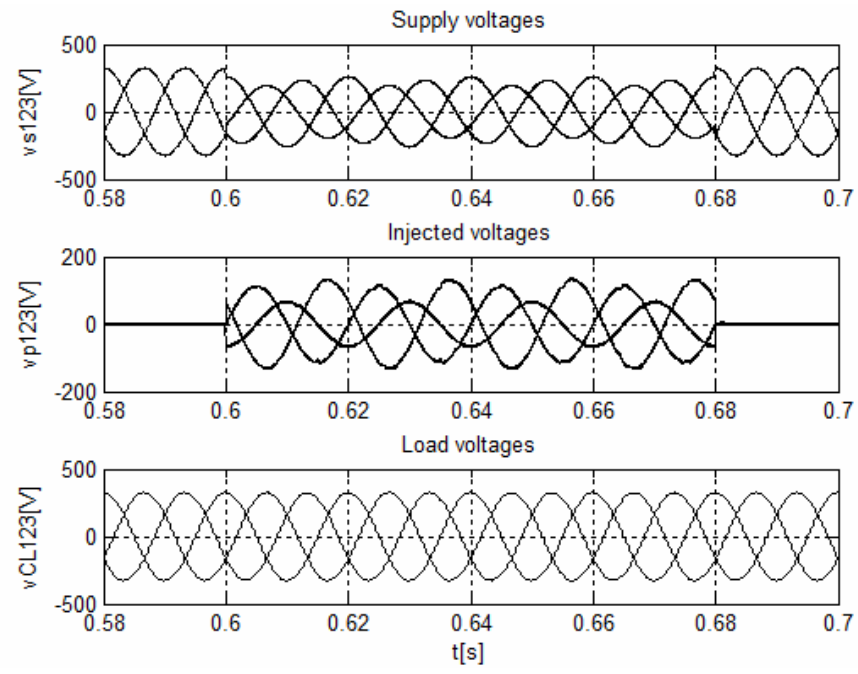

Fig. 15. Simulation result of DVR response to unbalanced voltage sag: Supply voltages $\left(v_{1}, v_{2}, v_{3}\right)$, Injected voltage $\left(v_{p 1}, v_{p 2}, v_{p 3}\right)$ and Load voltage $\left(v_{C L 1}, v_{C L 2}, v_{C L 3}\right)$.

\subsection{DVR response to voltage swells}

In the second test, the DVR performance for a voltage swell condition is investigated. A balanced voltage swell with $40 \%$ three-phase voltage increase, which starts at $0.6 \mathrm{~s}$ and ends at 0.68 s, is considered. For unbalanced swells, $50 \%$ (phase 1 ) and $20 \%$ (phase 2) voltage swell is considered. The performance of DVR is illustrated in Fig. 16 (balanced swell) and Fig. 17 (unbalanced swell).
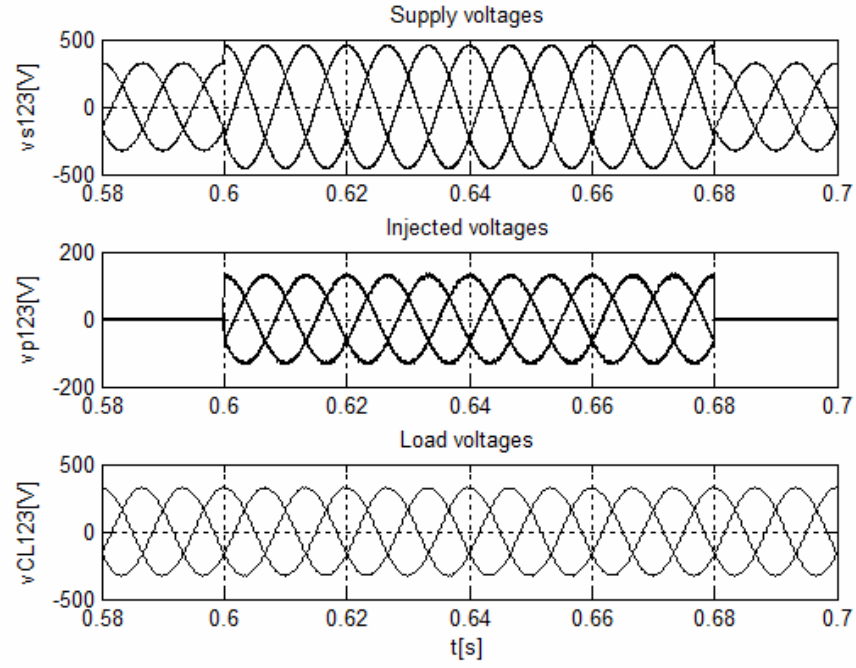

Fig. 16. Simulation result of DVR response to balanced voltage swell: Supply voltages $\left(v_{1}, v_{2}\right.$, $\left.v_{3}\right)$, Injected voltage $\left(v_{p 1}, v_{p 2}, v_{p 3}\right)$ and Load voltage $\left(v_{C L 1}, v_{C L 2}, v_{C L 3}\right)$. 
Again, the DVR injected voltage components $\left(v_{p 123}\right)$ compensate the critical load voltage $\left(v_{C L 123}\right)$ without showing any delays, voltage undershoots or overshoots. The DVR is able to correct the voltage swells showing response times far lower than the voltage supply period.
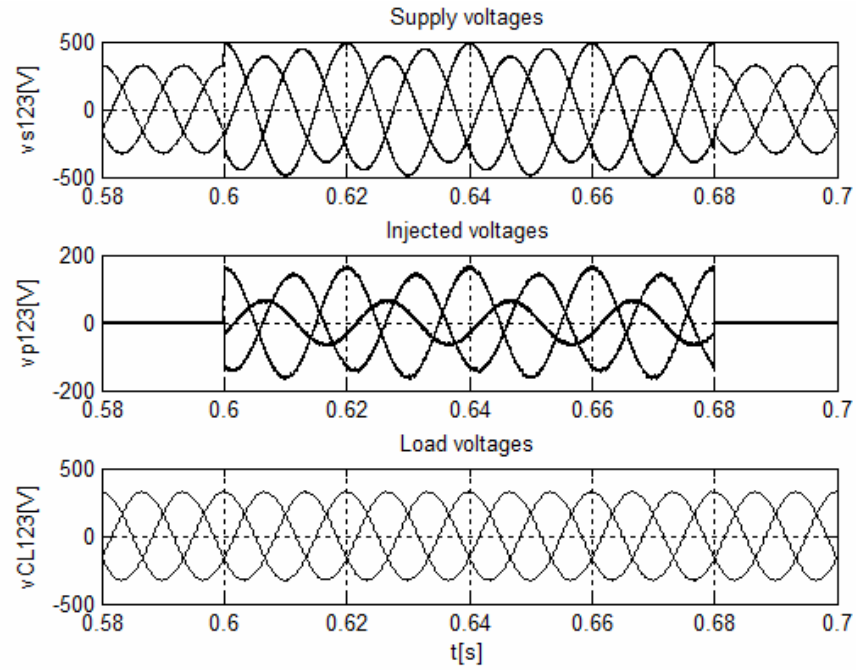

Fig. 17. Simulation result of DVR response to unbalanced voltage swell: Supply voltages $\left(v_{1}\right.$, $\left.v_{2}, v_{3}\right)$, Injected voltage $\left(v_{p 1}, v_{p 2}, v_{p 3}\right)$ and load voltage $\left(v_{C L 1}, v_{C L 2}, v_{C L 3}\right)$.

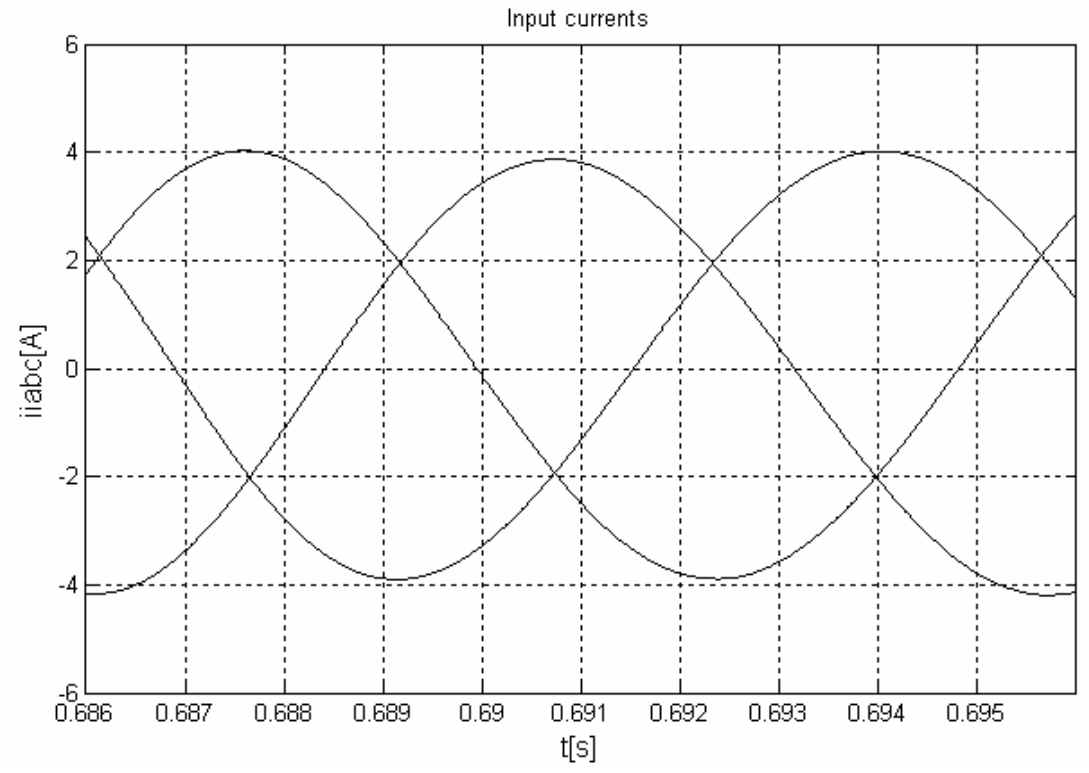

Fig. 18. Matrix input currents $\left(i_{i a}, i_{i b}, i_{i c}\right)$. 
Fig. 18 present the matrix input currents $\left(i_{i a}, i_{i b}, i_{i c}\right)$. Simulations show near sinusoidal input currents.

\subsection{Critical load voltage THD}

Fig. 19 presents the frequency spectrum of the critical load voltage. Besides the tracking capabilities of the predictive optimal control method, it presents a very useful characteristic, the very low harmonic content of critical load voltage. The spectrum shows the fundamental frequency at $50 \mathrm{~Hz}(100 \%)$ and some very low amplitude $(<1 \%)$ harmonics. The critical load voltage THD is less than $1 \%$.

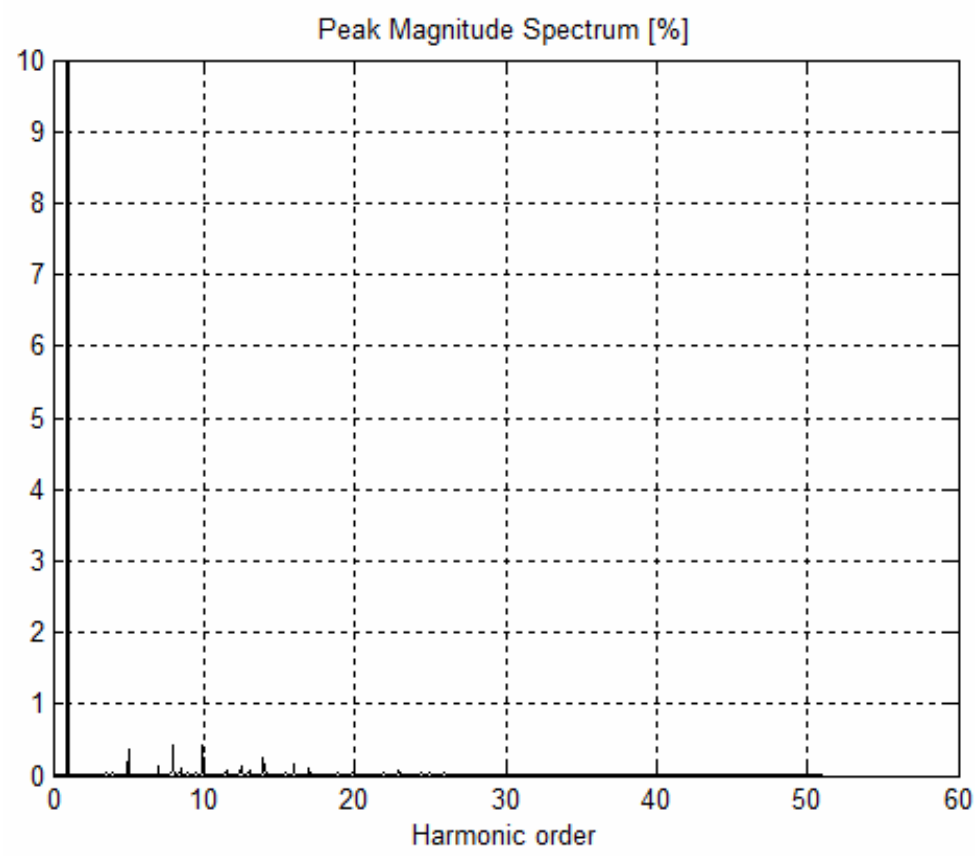

Fig. 19. Load voltage spectrum ( $\left.v_{C L 1}\right)$.

\section{Conclusions}

This Chapter has shown that predictive optimal control is a powerful control technique that will open new possibilities in the control of AC-AC matrix and other advanced power converters, as well as in the control of matrix driven permanent magnet synchronous motors. The predictive optimal control allows the control designer to overcome the matrix converter input/output coupling, easing the use of all the available converter vectors.

The presented predictive optimal control does not need any modulator. However, it achieves a very effective control of input and output currents and rotor speed. Therefore, the proposed technique is a good alternative for established control methods like hysteresis current control, sliding mode control and PWM control. 
A flywheel energy storage system, including a Permanent Magnet Synchronous Machine driven by the predictive optimal controlled matrix converter was used as a DVR to mitigate voltage sags, swells and THD. It was pointed out that the proposed predictive optimal matrix converter control presents very good performance when used in dynamic voltage restorers to mitigate voltage sags, swells and THD at critical loads, without showing delays, voltage undershoots or overshoots.

\section{References}

[1] R. Hebner, J. Beno, A. Walls (2006). "Flywheel batteries come around again", IEEE Spectrum, April 2002, pp. 46-51.

[2] T. Siostrzonek, S. Piróg (2006). "The Flywheel Energy Storage with Brushless DC Motor - the Practical Results", EPE-PEMC 2006 - September 2006, Portoroz, Slovenia.

[3] B. Wang, G. Venkataramanan (2007). “Dynamic Voltage Restorer Utilizing a Matrix Converter and Flywheel Energy Storage", Industry Applications Conference, 2007. 42nd IAS Annual Meeting. Conference Record of the 2007 IEEE, Volume, Issue , 23-27 Sept. 2007 Page(s):208-215.

[4] J. Silva, B. Borges,. Anunciada (1991). "Improving Control Strategies for HF Resonant Link Converters: the Current Mode Predictive Modulator", Power Electronics Specialists Conference, IEEE PESC'91, ISSN 0275-9306, pp 268-274, USA, June 1991.

[5] J. Rodriguez, J. Pontt, C. Silva, P. Cortés, and S. Rees (2004). "Predictive Current Control of a Voltage Source Inverter", 35th Annual IEEE Power Electronics Specialists Conference. Aachen, Germany, June 2004.

[6] J. Barros, J. Silva, S. Pinto (2005). "Real - Time Based Optimal Controller For Four Multilevel Converters", Proc. IEEE - CEE'05 - International Conference on Electrical Engineering - CEE05, CD-ROM paper 3w55, October 2005, Coimbra, Portugal.

[7] E. Wiechmann, A. Garcia, L. Salazar and J. Rodriguez (1997). “High-Performance DirectFrequency Converters Controlled by Predictive-Current Loop", IEEE Transactions on Power Electronics, Vol. 12, No. 3, May 1997.

[8] P. Gambôa, S. Pinto, J. Silva, E. Margato (2007). "Predictive Optimal Control of UnityPower-Factor Matrix Converters used in Field Oriented Controlled Induction Motor Drives", International Symposium on Industrial Electronics, Vigo, Spain, 4-7 June 2007.

[9] P. Gambôa, S. Pinto, J. Silva, E. Margato (2008). “A Flywheel Energy Storage System with Matrix Converter Controlled Permanent Magnet Synchronous Motor", ICEM08-XVIII International Conference on Electrical Machines, Vilamoura, Portugal, 6-9 September 2008.

[10] L. Huber, D. Borojevic, N. Burany, "Analysis, Design and Implementation of the SpaceVector Modulator for Forced-Commutated Cycloconverters" IEE Proceedings-B, Vol. 139, no 2, March 1992, pp. 103-113.

[11] P. Gambôa, S. Pinto, J. Silva, E. Margato (2009). "Predictive Optimal Matrix Converter Control for a Dynamic Voltage Restorer with Flywheel Energy Storage", The 35th Annual 
Conference of the IEEE Industrial Electronics Society, Porto, Portugal, 3-5 November 2009.

[12] Barros, J.D.; Silva, J.F.; "Multilevel Optimal Predictive Dynamic Voltage Restorer", Industrial Electronics, IEEE Transactions on, Aug. 2010, Volume: 57 Issue:8, pages: 2747 - 2760, ISSN: 0278-0046.

[13] S. F. Pinto, J. F. Silva, "Input Filter Design of a Mains Connected Matrix Converter", Session on Power Electronics Mitigation Methods for Power Quality, IEEE-Power Engineering Society International Conference on Harmonics and Quality of Power, October 2006, Cascais, Portugal. 


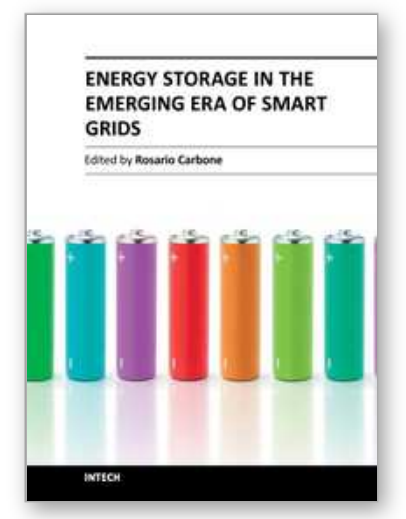

\author{
Energy Storage in the Emerging Era of Smart Grids \\ Edited by Prof. Rosario Carbone
}

ISBN 978-953-307-269-2

Hard cover, 478 pages

Publisher InTech

Published online 22, September, 2011

Published in print edition September, 2011

Reliable, high-efficient and cost-effective energy storage systems can undoubtedly play a crucial role for a large-scale integration on power systems of the emerging â€œdistributed generationâ€ (DG) and for enabling the starting and the consolidation of the new era of so called smart-grids. A non exhaustive list of benefits of the energy storage properly located on modern power systems with DG could be as follows: it can increase voltage control, frequency control and stability of power systems, it can reduce outages, it can allow the reduction of spinning reserves to meet peak power demands, it can reduce congestion on the transmission and distributions grids, it can release the stored energy when energy is most needed and expensive, it can improve power quality or service reliability for customers with high value processes or critical operations and so on. The main goal of the book is to give a date overview on: (I) basic and well proven energy storage systems, (II) recent advances on technologies for improving the effectiveness of energy storage devices, (III) practical applications of energy storage, in the emerging era of smart grids.

\title{
How to reference
}

In order to correctly reference this scholarly work, feel free to copy and paste the following:

Paulo Gambôa, J. Fernando Silva, S. Ferreira Pinto and Elmano Margato (2011). Predictive Optimal Matrix Converter Control for a Dynamic Voltage Restorer with Flywheel Energy Storage, Energy Storage in the Emerging Era of Smart Grids, Prof. Rosario Carbone (Ed.), ISBN: 978-953-307-269-2, InTech, Available from: http://www.intechopen.com/books/energy-storage-in-the-emerging-era-of-smart-grids/predictive-optimalmatrix-converter-control-for-a-dynamic-voltage-restorer-with-flywheel-energy-stor

\section{INTECH}

open science | open minds

\section{InTech Europe}

University Campus STeP Ri

Slavka Krautzeka 83/A

51000 Rijeka, Croatia

Phone: +385 (51) 770447

Fax: +385 (51) 686166

www.intechopen.com

\section{InTech China}

Unit 405, Office Block, Hotel Equatorial Shanghai

No.65, Yan An Road (West), Shanghai, 200040, China 中国上海市延安西路65号上海国际贵都大饭店办公楼 405 单元

Phone: +86-21-62489820

Fax: $+86-21-62489821$ 
(C) 2011 The Author(s). Licensee IntechOpen. This chapter is distributed under the terms of the Creative Commons Attribution-NonCommercialShareAlike-3.0 License, which permits use, distribution and reproduction for non-commercial purposes, provided the original is properly cited and derivative works building on this content are distributed under the same license. 